\title{
MEMBANGUN KEDALAMAN RUANG SEBAGAI REPRESENTASI KONFLIK INTERNAL DALAM PENYUTRADARAAN FILM FIKSI “HUMA AMAS”
}

\author{
Muhammad Al Fayed \\ Dyah Arum Retnowati \\ RR. Ari Prasetyowati \\ Jurusan Film \& Televisi, Fakultas Seni Media Rekam, Institut Seni Indonesia Yogyakarta \\ Jl. Parangtritis km. 6.5 Yogyakarta Telp. (0274) 381047
}

\begin{abstract}
ABSTRAK
Film fiksi atau film cerita adalah suatu film yang biasa digunakan untuk mengkomunikasikan tentang suatu realita yang terjadi dalam kehidupan masyarakat setiap harinya. Film fiksi "Huma Amas" ini bertujuan untuk menyuarakan isu yang terjadi di Kalimantan Timur yaitu tentang lingkungan dan masyarakat kecil khususnya daerah sekitar tambang batubara.

Karya film fiksi ini dalam visualisasinya menggunakan kedalaman ruang (depth of field) yang berbeda-beda sebagai representasi konflik internal tokoh utama. Hal ini bertujuan untuk memberikan impresi, makna, nuansa, emosional karakter dan memberikan penekanan konflik tokoh utama. Objek yang diangkat dalam karya film fiksi ini adalah masalah seorang petani yaitu Pak Yusni yang harus mengalami kebimbangan dan harus memilih untuk menjual tanah sawahnya kepada pihak tambang batubara atau mempertahankannya demi harta warisan keluarga.

Kedalaman ruang (depth of field) dan focal length pada lensa juga ikut meningkat dari penggunaan focal length $16 \mathrm{~mm}$ hingga $200 \mathrm{~mm}$. Meningkatnya focal length pada lensa dapat memberikan efek ilusi depth yang diciptakan dari lensa.
\end{abstract}

Kata Kunci : Penyutradaraan, Kedalaman Ruang, Konflik Internal, Film Fiksi.

\section{PENDAHULUAN}

Film adalah sebuah media yang bisa digunakan untuk menyampaikan sebuah pesan kepada masyarakat melalui sebuah cerita, dan film juga digunakan untuk merefleksikan realitas dan bahkan membentuk realitas. Film menjadi media yang mudah karena semua kalangan masyarakat dapat menerima sebagai hiburan, ilmu dan wawasan. Film juga menjadi media para seniman atau pembuat film untuk menyuarakan isu atau masalah tertentu, seperti isu HAM, lingkungan, hewan langka, pabrik, hutan, tambang dan lain-lain.

Kalimantan Timur (Kaltim) salah satu provinsi di Indonesia yang mempunyai kekayaan alam yang luar biasa. Sejak tahun 1990 hingga saat ini, Kaltim bergantung pada sektor ekonomi berbasis sumber daya tak terbarukan seperti batu bara, kelapa sawit, minyak dan gas. Pertumbuhan ekonomi Kaltim bila dilihat tahun belakang ini yakni tahun 2008 sampai 2012 sempat mengalami pertumbuhan yang tinggi akibat banyaknya industri tambang batubara. Bahkan, provinsi 


\section{Muhammad Al Fayed, Dyah Arum Retnowati, RR. Ari Prasetyowati}

Membangun Kedalaman Ruang Sebagai Representasi Konflik Internal Dalam Penyutradaraan Film Fiksi

Kalimantan Timur menjadi salah satu daerah dengan pertumbuhan ekonomi tertinggi seIndonesia (Yovanda. 2018).

Menurut laporan dari berbagai daerah ada 264 lubang di Kabupaten Kutai Kartanegara, 164 di Samarinda, 86 di Kutai Timur, 46 di Paser, 36 di Kutai Barat, 24 di Berau dan Panajam Paser Utara ada 1 lubang dan itu masih bisa bertambah lagi. Sampai tahun 2019 kurang lebih 232 bekas lubang tambang batubara yang masih menganga hingga menjadi danau (Yovanda. 2018). Sampai saat ini telah menelan 36 korban di antaranya orang dewasa, remaja dan anakanak (Harian Kompas, Kompas). Tidak satu pun dari kasus ini mendapatkan hukuman dan sanksi yang setimpal bagi para perusahaan yang tak menutup kembali bekas lubang tambang mereka.

Berdasarkan persoalan di atas, memunculkan ide untuk membuat naskah "Lubang Bara" (Huma Amas) yang mengangkat isu di Kalimantan Timur. Bercerita tentang beberapa petani padi yang lahannya bersampingan dengan tambang batubara, mengeluhkan tanah dan air pada lahan padi mereka menjadi tidak bagus. Menyebabkan kualitas padi yang dihasilkan menjadi buruk. Diambil juga dari kejadian nyata Bapak Bahar di Makroman, Samarinda dan anak yang tewas pada lubang danau bekas galian tambang batubara, selain itu juga dari kejadian nyata keluarga Ibu Rahmawati yang anaknya menjadi korban yaitu bernama Muhammad Raihan, yang sudah pernah dibuat juga film dokumenternya berjudul "Emas Hitam" karya Ahmad Fauzan Perdana dari mahasiswa ISBI Kalimantan Timur.

Ketertarikan dalam menyutradarai naskah film fiksi "Lubang Bara" ini selain isu yang kuat di daerah tersebut. Naskah ini mempunyai struktur plot dan dramatik yang permasalahannya semakin meningkat dan banyak pada tokoh utama. Teknik kedalaman ruang yang menjadi gaya penyutradaraan nantinya dapat dipadukan, karena dapat membangun mise en scene dua plot yang dibuat dramatik, ruang dan waktu dipadukan agar memberikan perhatian penonton dalam melihat visual yang ditampilkan. Teknik kedalaman ruang yang di terapkan pada naskah film "Lubang Bara" akan membangkitkan rasa ingin tahu dan memberikan interpretasi baru bagi penonton di saat perubahan kedalaman ruangnya meningkat. Perubahan kedalaman ruang akan selalu bertambah setiap naiknya babak pada tangga dramatik, menjadikan bentuk representasi hasil dari perubahan atau meningkatnya konflik batin pada masingmasing tokoh. Teknik kedalaman ruang akan membuat perspektif berbeda yang hadir dalam visual yang akan dirasakan penonton dari konflik internal tokoh melalui kedalaman ruang yang akan dibangun di naskah ini. 
Naskah film fiksi "Lubang Bara" akan difilmkan dengan judul "Huma Amas", akan menggunakan kedalaman ruang sebagai representasi konflik internal atau konflik batin yang dirasakan pada tokoh utama dalam film. Film ini mengisahkan tentang seorang ayah dan anak yang ditimpa berbagai masalah dalam kehidupan sosialnya.

Film ini dikemas dengan tema keluarga dari kalangan menengah ke bawah yang menceritakan seorang Bapak bernama Pak Yusni, yang mempunyai anak bernama Aji. Yusni adalah seorang petani yang akan mengalami gagal panen dan di ajak bekerja bersama tambang batubara, sedangkan Aji mengalami masalah pada teman-temannya karena pengaruh kondisi keluarganya yang kurang mampu membuat Aji dikucilkan dengan teman-temannya.

Film ini akan dikemas dengan struktur cerita pola linier. Pola linier banyak digunakan dalam membuat skenario untuk cerita semacam FTV, film, atau serial lepas. Selain itu, setiap adegan dalam film "Huma Amas" nantinya sutradara akan memvisualisasikan dengan kedalaman ruang yang berbeda-beda dengan menggunakan perubahan focal length dari $16-24 \mathrm{~mm}, 24-$ 50mm, 50-100mm dan 100-200mm yang akan mempengaruhi impresi, makna, nuansa, emosional karakter, dan memberikan sebuah penekanan konflik yang dihadapi oleh tokoh pada cerita (Mercado, 2011:13).
Film ini dalam proses pembuatannya akan berdasarkan kehidupan realita yang terjadi pada masyarakat aslinya di Kalimantan Timur, sehingga film ini terlihat lebih dekat dengan penonton, akan terasa lebih nyata, seperti dalam kehidupan seharihari dari segi pengadeganan. Penggunaan setting lokasi diambil langsung di Kalimantan Timur. Penggunaan lensa sebagai alat yang membangun kedalaman ruang dimensi dari nuansa yang ada di film dibantu dengan aspek-aspek lainnya seperti sinematografi, tata cahaya, artistik, editing dan tata suara sehingga pesan yang disampaikan dapat diterima dengan jelas serta membawa penonton dapat dengan mudah masuk ke dalam film ini.

Skenario film fiksi "Lubang Bara" menggunakan penceritaan linear dengan alur cerita ganda di mana ada alur cerita Pak Yusni dan alur cerita Aji. Alur linear pada umumnya semua porsi cerita dan karakter memiliki keseimbangan, dua karakter pada skenario ini memiliki peranan penting dalam sebab akibat yang akan terjadi pada cerita. Awal sampai akhir cerita penonton akan diajak mengikuti alur pada masing-masing plot yang berjalan bersamaan melalui penyusunan editing yang bergantian tiap scene milik karakter. Ditambah lagi beberapa scene pada skenario ini mempertemukan dua tokoh utama ini guna untuk memperkuat sumber masalah internal yang ada di keluarga Pak Yusni dan Aji, lalu sumber permasalahan 


\section{Muhammad Al Fayed, Dyah Arum Retnowati, RR. Ari Prasetyowati}

Membangun Kedalaman Ruang Sebagai Representasi Konflik Internal Dalam Penyutradaraan Film Fiksi

yang terjadi pada internal keluarga terbawa dari faktor eksternal dikehidupan dua karakter tokoh utama ini.

Berawal dari salah satu teman petaninya Pak Yusni yang dikabarkan menjual tanah sawahnya ke pihak tambang yang berada persis di tanah sawah para petani desa itu. Pak Syahrul teman dekat Pak Yusni juga memberitahu bahwa tanah sawah miliknya juga akan di beli dengan pihak tambang dan dari situlah permasalahan yang terjadi pada Pak Yusni di mulai. Aji berawal dari salah satu teman sekolah sekaligus mainnya, mengajak bermain mobil truk remote di danau bekas tambang dekat desa mereka.

Tokoh Aji yang tidak memiliki mobil truk remote seperti teman-temannya, Aji pun di ejek dan di tekan untuk segera mempunyai mainan yang sama. Film fiksi "Huma Amas" menggunakan skema dramatik penuturan tiga babak, yaitu pengenalan, konflik, dan penyelesaian.

Sebagai karya tugas akhir, karya ini diperkuat pada bagian emosi tokoh Pak Yusni dan Aji dengan menggunakan kedalaman ruang sebagai representasi konflik internal (batin) tokoh Pak Yusni dan Aji pada cerita film fiksi "Huma Amas". Penggunaan teknik kedalaman ruang akan bertambah setiap naiknya scene dan plot menjadi konsep yang akan direalisasikan dalam penciptaan film fiksi "Huma Amas", skenario yang dimiliki film fiksi "Huma
Amas" memiliki pola naratif linier bagaimana pola tersebut diinterpretasikan dengan kedalaman ruang yang selalu menambah dan naik dengan teknik alat yaitu focal length lensa yang semakin panjang (dari 14-200mm).

Kedalaman ruang tersebut tidak hanya menjadi representasi dari focal length lensa saja, tetapi efek dari focal length lensa dari jarak focal length $14 \mathrm{~mm}$ sampai dengan $200 \mathrm{~mm}$ memiliki efek foreground, midground dan background yang berbeda pada setiap lensa, lensa akan memberikan perubahan kepada frame yang direkam. Perubahan dan efek tersebut yang akan menjadi representasi emosi, perasaan, masalah dan konflik internal (batin) yang dirasakan tokoh Pak Yusni dan Aji terus semakin banyak dan dalam.

Awal pembuatan skenario ini sutradara dan produser memutuskan untuk menggunakan lokasi set di Kalimantan Timur dan menggunakan campuran bahasa maupun logat lokal di kota Samarinda yaitu, bahasa Banjar untuk lebih menekankan sosial budaya yang menjadi salah satu keunggulan dari skenario film fiksi "Huma Amas" ini. Karena penggunaan lokasi set asli di Kalimantan Timur dan dialog berbahasa Kalimantan Timur adalah salah satu bagian penting untuk mendukung dalam aspek realitas setting lokasi dan tiga dimensi tokoh yang memang menjadi tujuan sutradara. 


\section{KONSEP KARYA}

Film "Huma Amas" menekankan pada aspek cara berpikir kreatif dalam menceritakan suatu kejadian serta ide-ide yang beraneka macam. Dengan penceritaan multi plot merupakan bentuk cara pengemasan film. Maka pada prosesnya sutradara memberikan kebebasan kepada aktor untuk memerankan tokoh sesuai dengan karakter. Hal ini bertujuan memperoleh gestur serta dialog yang seharihari mereka lakukan dan menampakan kehidupan sebenarnya yang terjadi pada cerita. Konsep penyutradaraan yang digunakan dalam film fiksi "Huma Amas" lebih menekankan pada konsep konflik internal (batin) tokoh utama sebagai penggerak cerita.

Film "Huma Amas" ini tidak hanya memperhatikan soal adegan saja, namun aspek penataan gambar, editing serta musik juga akan berpengaruh dalam memperkuat dramatik pada film ini. Pertama-tama sutradara berkomunikasi dengan semua kru sekaligus para aktor dan aktris dalam pembuatan film mulai dari praproduksi hingga pascaproduksi. Semua aspek seperti penataan kamera, cahaya, setting, editing, suara dan musik ditentukan sutradara dengan diskusi bersama para kru yang sesuai dengan job desk dan divisi pada pembuatan film.

Sutradara tidak hanya berfokus pada konsep penuturan, penceritaan dan pengadeganannya saja. Sutradara juga harus paham dengan apa yang ia visualkan. Konsep visual dari sutradara biasanya memiliki treatment tersendiri sesuai karakter dan gaya penyutradaraannya, konsep visual yang digunakan pada film ini yaitu menggunakan teknik kedalaman ruang sebagai representasi konflik internal atau batin. Teknik kedalaman ruang akan merepresentasikan bagaimana konflik batin yang dirasakan tokoh utama, semakin banyaknya konflik batin yang dirasakan tokoh Pak Yusni dan Aji, kedalaman ruang yang dibangun dalam film akan semakin dalam (foreground dan background yang semakin mendekat atau membesar). Dalam hal ini alat utama sutradara adalah menggunakan lensa, untuk menciptakan kedalaman ruang yang terlihat di visual, penggunaan lensa nantinya sutradara menetapkan pada range 16 24mm, 24 - 50mm, 50 - 100mm dan 100 200mm untuk mencapai peningkatan tangga dramatik dan emosi konflik batin tokoh utama.

Berdasarkan proses perubahan kedalaman ruang tersebut sutradara guna merepresentasikan konflik batin yang dirasakan tokoh utama, sutradara akan menentukan penempatan range focal length dalam naiknya plot tangga dramatik di beberapa scene yaitu scene 1-4 (babak perkenalan), scene 5-10 (babak turning point 1), scene 11-22 (babak turning point 2) dan scene 23-28 (babak klimaks dan penyelesaian). Gambar dibawah 


\section{Muhammad Al Fayed, Dyah Arum Retnowati, RR. Ari Prasetyowati}

Membangun Kedalaman Ruang Sebagai Representasi Konflik Internal Dalam Penyutradaraan Film Fiksi

perbandingan perubahan efek dari lensa $15 \mathrm{~mm}$ sampai dengan $180 \mathrm{~mm}$.

\section{PEMBAHASAN HASIL PENCIPTAAN}

Visi besar tentang konflik internal atau konflik batin uang diterapkan pada cerita ini sudah di eksplorasi dari proses awal pembentukan naskah, di mana semua plot Pak Yusni dan sub plot Aji selalu naik atau menambahnya masalah hingga klimaks dan penyelesaian. Membuat para karakter utama dengan sifat karakter yang pendiam dan menerima keadaan semakin menambah konflik batin yang dirasakan karakter mereka dengan alur cerita tersebut. Hal tersebut di eksplorasi juga pada visual storytelling, dari sisi konsep kedalaman ruang, blocking level, blocking position, angle, dan shot size.

Kedalaman ruang yang dibangun sebagai representasi konflik internal atau konflik batin, alat utamanya sutradara saat produksi yaitu merancang dan menentukan focal length lensa sebelum produksi dan di eksekusi oleh director of photography, saat produksi beberapa lokasi yang tidak memungkinkan rancangan konsep focal length lensa yang di inginkan sutradara di awal membuat adanya perkembangan dan perubahan range focal length yang direncanakan.

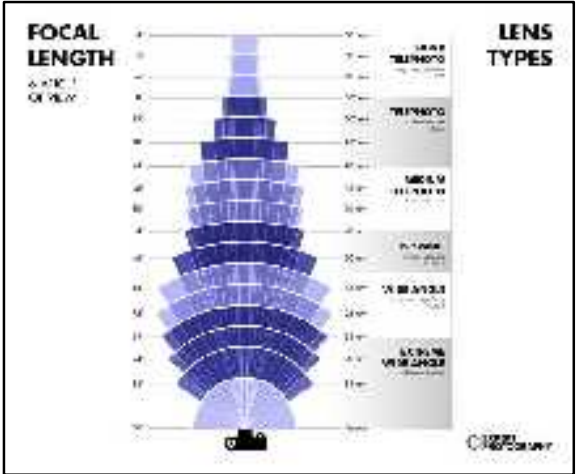

Gambar 1. Gambar diagram dari macam-macam focal length pada lensa www.expertphotography.com diakses pada 3

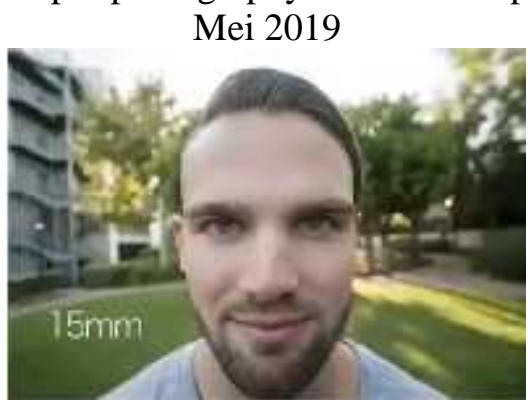

Gambar 2. capture efek lensa focal length $15 \mathrm{~mm}$ www.darrenmillerfilms.com diakses pada $7 \mathrm{Mei}$ 2019

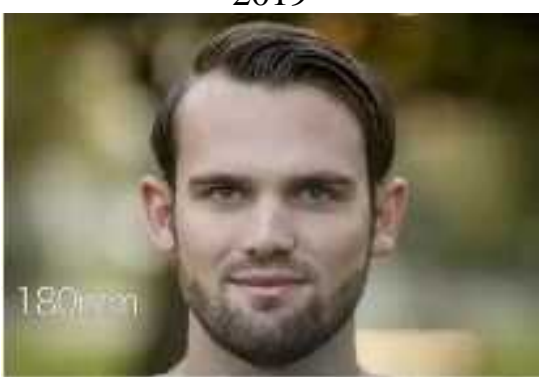

Gambar 3. capture efek lensa focal length $200 \mathrm{~mm}$

www.darrenmillerfilms.com diakses pada 7 Mei 2019

Proses pengembangannya naratif pada karya film fiksi ini menjadi memiliki sinopsis yang berbeda dari versi naskah final draft begitu pula dengan judul film "Huma Amas" yang sebelumnya "Lubang Bara", perubahan judul tersebut diganti dengan berbagai pertimbangan dengan alasan utama terlalu eksplisit membicarakan tambang batubara. Alasan tersebut menjadikan judul "Huma Aamas" terpilih karena tidak terlalu eksplisit dan punya makna yang dalam. 
Perubahan sinopsis terjadi pada versi pict lock film fiksi "Huma Amas" ini bercerita tentang Pak Yusni (40) seorang petani yang sedang bimbang lantaran harus mempertahankan tanah warisan keluarganya atau menjualnya kepada pihak perusahaan tambang batubara yang terus gencar memberi tawaran. Pak Syahrul (45) sudah melepas tanah miliknya, Aji (9) anak pak Yusni yang meminta untuk dibelikan mobil remote, kerugian sawah akibat bersampingan tambang batubara dan segala tawaran pihak perusahaan akhirnya membuat Pak Yusni tak ada pilihan lain selain menjual tanahnya kepada pihak perusahaan. Akhirnya Pak Yusni memutuskan untuk memilih bekerja sebagai buruh pencuci truk yang sebenarnya membuat tak nyaman dirasakan oleh Pak Yusni sendiri.

Secara garis besar, kedalaman ruang adalah istilah yang menunjukan ruang tertentu di dalam frame yang tampak relatif tajam karena adanya ketajaman (fokus). Walaupun sebuah lensa hanya mempunyai satu fokus yang presisi, yaitu bidang fokus yang berada pada satu jarak fokus (focal distance) tertentu, penurunan ketajaman sebuah frame juga disebut out focus atau orang awam sebut bokeh. Bagaimana ruang tiga dimensi di tangkap menjadi sebuah frame yang memiliki dua dimensi, menimbulkan efek focus dan out focus. Efek depth of field mengacu pada focal length yang diberikan lensa manapun, maka senjata utama sutradara untuk menyampaikan visi merepresentasikan konflik internal atau batin yaitu lensa.

Eksposisi / Pengenalan (scene 1 - 4)

Scene 2

SC3. EXT. KEBUN SINGKONG - PAGI HARI (on script)

Scene 2 ini dimulai dengan long shot tambang batubara yang sedang beroperasi, dilanjutkan dengan group shot terlihat Pak Yusni sedang berdiri melihat ke arah kanan frame dilanjutkan dengan kedatangan Pak Syahrul ia adalah teman petani Pak Yusni juga memandang ke arah yang sama. Pak Syahrul mengawali pembicaraan perihal pupuk yang tak berguna lagi di kebun dan sawah mereka, dilanjutkan dengan Pak Yusni yang membicarakan untuk membeli air pun mahal. Dalam situasi ini konflik internal yang dirasakan Pak Yusni tidak hanya dalam dirinya dan keluarganya saja, tetapi faktor eksternal ternyata juga mempengaruhi dalam diri Pak Yusni.

Pak Yusni membahas air karena air yang ia konsumsi di rumah bersama anaknya Aji air yang berasal dari sumber air yang sekarang terkena limbah batubara, hal tersebut diambil dari kejadian nyata di Desa Mulawarman, Kalimantan Timur. Pak Yusni hanya mengatakan kepada Pak Syahrul bahwa air susah didapatkan, tidak membicarakan apa yang ia konsumsi bersama keluarganya. Di sisi lain hal yang sama juga terjadi pada dirinya sebagai petani 


\section{Muhammad Al Fayed, Dyah Arum Retnowati, RR. Ari Prasetyowati}

Membangun Kedalaman Ruang Sebagai Representasi Konflik Internal Dalam Penyutradaraan Film Fiksi

karena pupuk menjadi percuma karena kerusakan alam yang terus menerus merusak sawah mereka membuat keuntungan panen mereka berkurang.

Scene ini, kedalaman ruang sebagai representasi konflik internal Pak Yusni menggunakan focal length lensa $16 \mathrm{~mm}$ dan $24 \mathrm{~mm}$ dengan di $\mathrm{f} / 2-5.6$ untuk tetap menciptakan ruang antara objek, foreground dan background. Lensa tersebut dikategorikan wide lens, dimana wide lens termasuk lensa yang untuk mengambil gambar yang luas dengan ketajaman yang luas pula (deep focus). Lensa wide digunakan juga pada frame dialog karena konsep pada diri karakter juga sama persis dengan tujuan dan efek yang terlihat pada lensa, bahwa lensa dengan focal length kecil dan memiliki titik fokus yang luas menginterpretasikan masalah yang terjadi pada Pak Yusni masih luas, masih jauh dan masih sedikit pada scene ini.

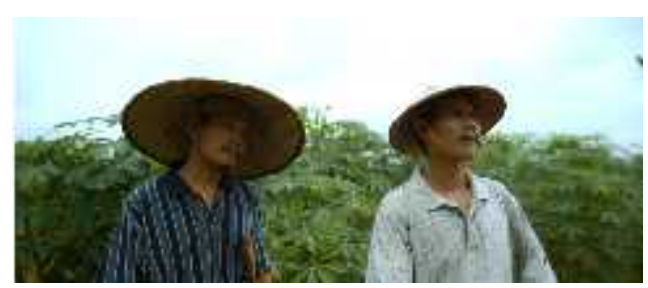

Gambar 4. Shot 1 yang diambil pada scene 2

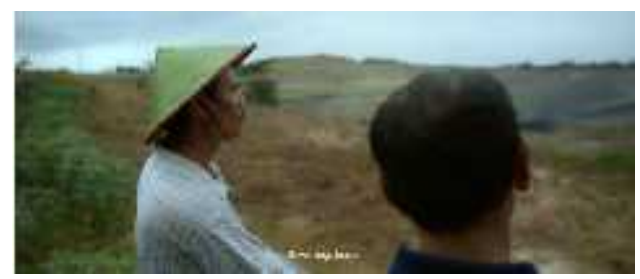

Gambar 5. Shot 2 yang diambil pada scene 2

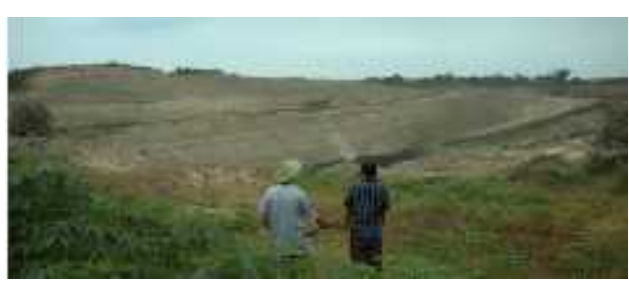

Gambar 6. Shot 3 yang diambil pada scene 2

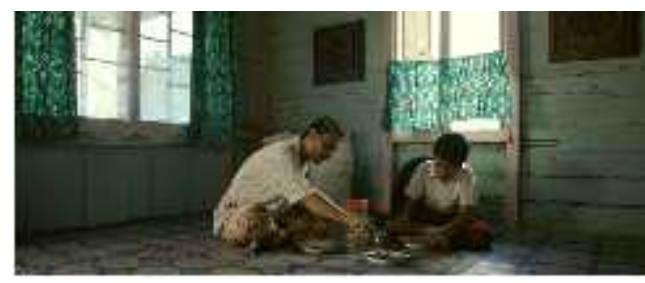

Gambar 7. Salah satu shot yang diambil pada scene 5

Turning Point 1 (scene 5 - 10)

Scene 5

SC2. INT. RUMAH - PAGI HARI (on script)

Scene 5 diawali dengan shot establish rumah Pak Yusni dari depan, sebagai shot pengenalan rumah Pak Yusni dan Aji. Setelah dari shot tersebut terlihat Pak Yusni dan Aji sedang makan di ruang tengah rumah mereka, Aji dengan pelan ingin mempunyai mobil remote yang dia inginkan namun Pak Yusni hanya bisa menjawab nanti dan lain kali saja untuk mainan yang di inginkan Aji.

Dialog awal Aji meminta mobil remote nya ditahan pada shot master terlihat mereka berdua bahwa masalah muncul di babak Turning Point 1 adalah pada diri mereka Pak Yusni dan Aji. Bahwa masalah tersebut menjadi masalah paling kuat pada batin mereka karena mempunyai beban antara ayah dan anak dan begitu kebalikannya anak dan ayah. Mereka berdua punya disisi lain punya kedekatan darah, namun kedekatan emosional karena punya karakter yang sama 
menjadi tidak cocok dan saling menyimpan masalahnya sendiri-sendiri.

Setelah dari shot master Pak Yusni dan Aji, lalu pindah dengan shot cover mereka berdua. Scene 5 ini adalah scene 2, di pindahkan karena scene awal pada film mendapat pengembangan naratif yang lebih sesuai yaitu lebih baik film "Huma Amas" fokus pada satu karakter yaitu Pak Yusni agar tidak terlalu kompleks menceritakan langsung dua sisi anak dan ayah pada satu film pendek.

Aspek kedalaman ruang ditempakannya scene 2 di scene 5 menjadi pengembangan posisi dimana babak turning point 1 diawali dengan kedalaman ruang yang memiliki focal length luas yaitu 16-24mm, di mana kedalaman tersebut menjadi dasar pengenalan karakter pada babak eksposisi menjadi awal sebuah permasalahan yang terjadi selanjutnya, sesuai dengan posisi scene pada awal babak turning point 1 .

Turning Point 2 (scene 11 - 22)

Scene 11

SC13. EXT. GUBUG SAWAH - SORE (on script)

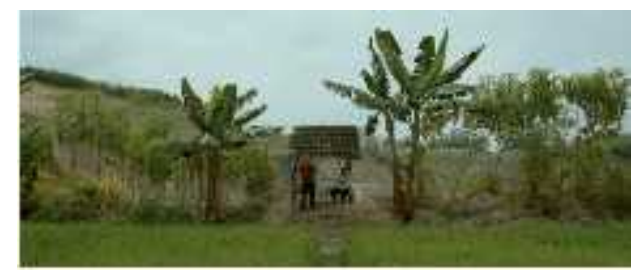

Gambar 8. Shot 1 yang diambil pada scene 11

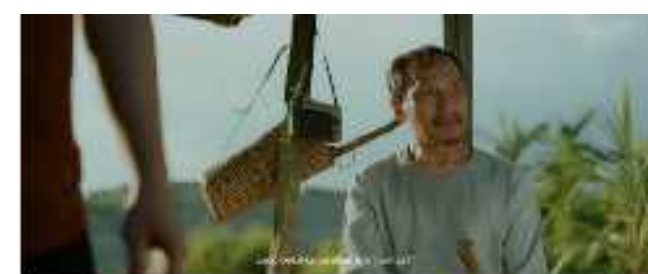

Gambar 9. Shot 2 yang diambil pada scene 11

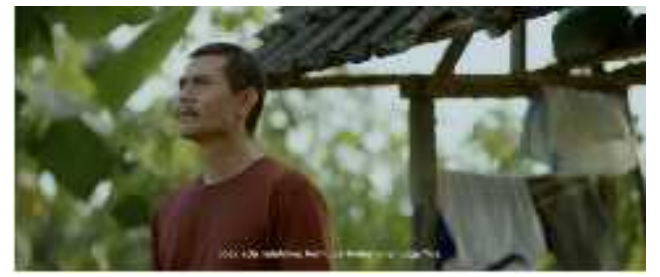

Gambar 10. Shot 3 yang diambil pada scene 11

Scene 11 ini shot diawali kembali seperti scene gubug sebelumnya, dengan master shot hingga dialog tiba dari Pak Syahrul yang memberitahu bahwa istrinya setuju menjual tanah sawahnya, dialog tersebut menjadi ajakan dan ketidaknyamanan Pak Syahrul atas keputusannya untuk menjual. Kondisi yang membuat para petani tidak bisa berbuat apaapa dan kualitas hasil panen yang semakin turun pun menjadi pertimbangan Pak Syahrul, dengan keputusan tersebut ia juga mencoba menyuruh Pak Yusni mempertimbang kan lagi untuk ikut menjual tanahnya.

Konflik yang dirasakan Pak Yusni sudah dimulai pada shot pertama, dengan adegan tetap berdiri di depan gubug, lalu mendengarkan Pak Syahrul berbicara. Setelah itu di tekan kan kembali dengan shot medium close up Pak Yusni memperlihatkan bagaimana ekspresi dan apa yang dipikirkannya perihal konflik batinnya, konflik batin yang muncul pada diri Pak 


\section{Muhammad Al Fayed, Dyah Arum Retnowati, RR. Ari Prasetyowati}

Membangun Kedalaman Ruang Sebagai Representasi Konflik Internal Dalam Penyutradaraan Film Fiksi

Yusni yaitu ia mendengar terkejut bahwa teman bertaninya juga ikut menjual, dengan terpaksa ia kemungkinan juga akan menjual karena banyak faktor. Faktor tersebut dari Aji, tanah warisan, kualitas yang semakin rusak, penawaran dari perusahaan tambang dan yang terbaru yaitu Pak Syahrul ikut menjualnya.

Kedalaman ruang yang dibangun pada scene ini dengan focal length $50 \mathrm{~mm}, 85 \mathrm{~mm}$ dan $100 \mathrm{~mm}$. Beberapa pengecualian dengan shot pertama scene ini karena komposisi yang sama seperti scene sebelumnya di gubug, menjadi kan focal length lensa tetap pada $35 \mathrm{~mm}$. Salah satu shot cover Pak Yusni dan Pak Syahrul menggunakan focal length lensa $50 \mathrm{~mm}$ dan $85 \mathrm{~mm}$ untuk meningkatkan kedalaman ruang sesuai dengan meningkatnya babak dan masalah yang terjadi pada tokoh utama.

\section{Scene 17}

SC23. INT. KAMAR AJI - MALAM HARI (on script)

Scene ini Pak Yusni mencoba untuk masuk ke kamar Aji untuk melihat Aji dan memberikan mainan mobil remote. Ia taruh di meja samping kasur Aji lalu keluar dengan penuh renungan. Adegan tersebut juga di isi dengan voice over Pak Yusni yang ingin membahagiakan Aji sebagai anak satusatunya yang ia miliki.

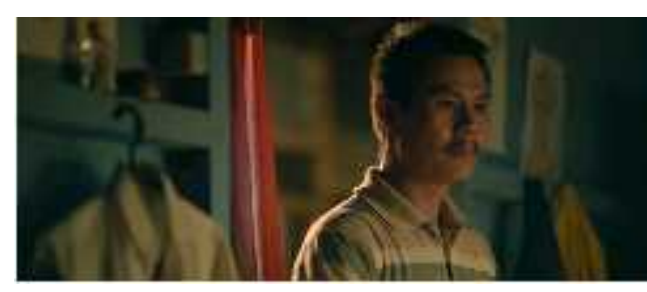

Gambar 11. Shot 1 yang diambil pada scene 17

Scene ini juga menjadi yang dipindahkan karena pengembangan naratif yang lebih sesuai dan lebih fokus ke terhadap penjualan tanah yang akan dilakukannya setelah ini, menjadikan masalah rumah dan keluarga harus diselesaikan terlebih dahulu sebelum menuju masalah berikutnya. Setelah memberikan Pak Yusni keluar kamar dan termenung sendiri, karena ia juga harus memikirkan masalah lainnya seperti menjual tanah sawahnya dan bekerja di perusahaan tambang.

Kedalaman ruang yang dibangun penggunaan focal length $50 \mathrm{~mm}-100 \mathrm{~mm}$, namun focal length $100 \mathrm{~mm}$ digunakan pada shot detil close up mainan mobil remote. Beberapa shot dibuat dengan konsep frame by frame, dimana shot tersebut mengkomposisikan dan ditujukan ke seorang Pak Yusni saja, seperti Pak Yusni di antara pintu kamar (pintu kamar menjadi foreground) dan Pak Yusni terlihat di dalam sebuah persegi yang mengartikan mengotakan dirinya pada masalah ini.

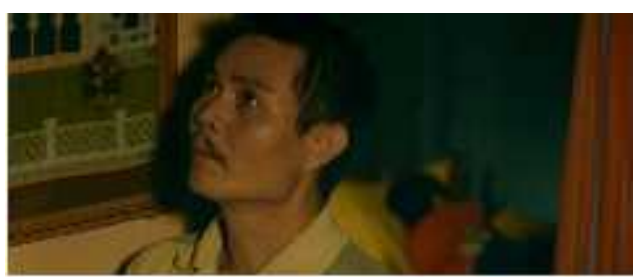

Gambar 12. Shot 2 yang diambil pada scene 17 
Klimaks dan Penyelesaian

(scene 23-28)

Scene 28

SC27. EXT. KEBUN SINGKONG - SIANG

HARI (on script)

Scene 28 film ini yaitu scene 27 pada naskah, di mana scene 28 pada film ini menjadi scene ending dalam film. Scene 28 pada naskah dengan adegan Aji yang bermain sendiri dan tak sengaja tergelincir dan jatuh ke danau bekas tambang batubara. Film fiksi "Huma Amas" memiliki pengembangan proses pasca produksi untuk menghilangkan scene 28 pada film, karena ingin memberikan penyelesaian kepada masalah Pak Yusni saja, penyelesaian masalah Aji hanya sampai pada scene 25 bagaimana Aji bersedih karena bermain sendirian.

Scene 28 memiliki adegan Pak Yusni memegang amplop upah atas pekerjaannya sebagai buruh cuci truk tambang batubara. Scene di awali dengan shot close up amplop sebagai penyambung graphical match dari shot dan scene sebelumnya yaitu scene 27 , dengan akhir scene shot medium close up Pak Yusni merenung lalu melihat amplop yang dipegangnya.

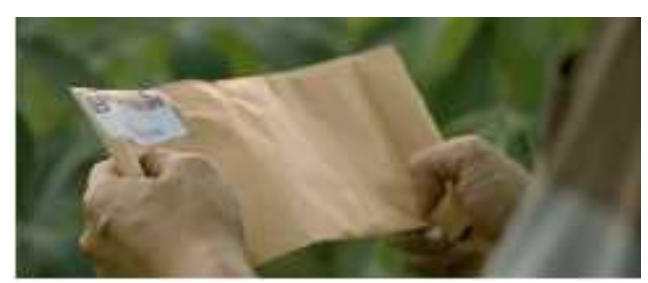

Gambar 13. Shot 1 yang diambil pada scene 28
Kedalaman ruang yang dibangun pada scene ini telah pada puncaknya yaitu dengan focal length lensa 100-200mm, dimana shot close up amplop menggunakan lensa 100mm dan shot cover Pak Yusni dan baliho kepemilikan tanah perusahaan tambang menggunakan lensa $200 \mathrm{~mm}$ dengan menggunakan teknik rack fokus karena ada perpindahan focus objek.

Shot selanjutnya shot close up ekspresi Pak Yusni dengan menggunakan lensa $100 \mathrm{~mm}$, karena ingin mendapatkan gambar yang detail pada wajah Pak Yusni sekaligus memfokuskan objek dari background lainya, efek blur yang semakin dalam dan bokeh menjadi titik tajam yang dilihat penonton hanya wajah Pak Yusni yang beradegan sedang melihat ke arah tambang batubara berada disamping sawah miliknya.

Film ini ditutup dengan full shot dari belakang badan Pak Yusni yang menghadap ke arah tambang batubara, shot tersebut menjadi repetisi sekaligus perbandingan kedalaman ruang dengan scene 2 yang efeknya sangat berbeda antara lensa $16 \mathrm{~mm}$ dan 200mm. Kedalaman ruang yang semakin tinggi dan panjang focal length nya membuat foreground dan background terlihat semakin sangat dekat, hal itu menjadi visi sutradara untuk interpretasikan emosi Pak Yusni yang semakin banyak, tinggi dan sangat dekat pada dirinya. 


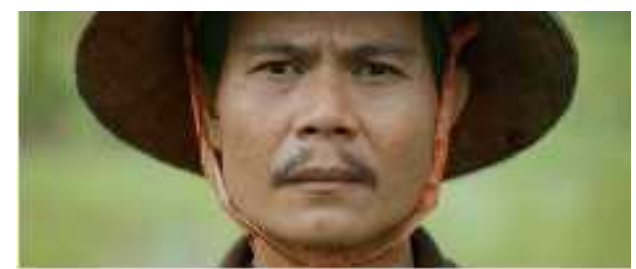

Gambar 14. Shot 2 yang diambil pada scene 28

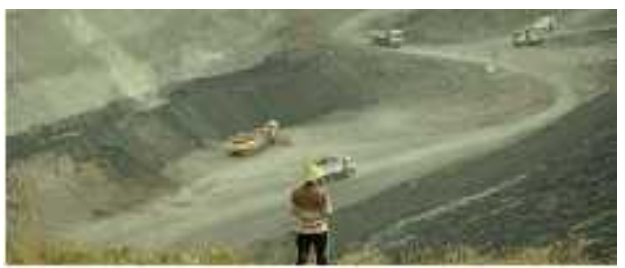

Gambar 15. Shot 3 yang diambil pada scene 28

Konsep awal visi sutradara atas pembangunan kedalaman ruang dibangun tokoh Pak Yusni memiliki grafik terus naik bersamaan dengan karakter lainnya yaitu tokoh Aji. Pengembangan terbaru saat ini grafik tersebut tidak terus naik seperti konsep awal sutradara dari scene 1-28 atau anggap dengan hitungan angka 0-100, namun pengembangan yang terbaru menjadi beberapa scene yang di tukar. Kedalaman ruang juga ikut berubah beserta naratif yang berubah, membuat ke grafik yang terus naik menjadi berubah di versi film yang terbaru. Berikut grafik yang dibuat dari konsep rancangan dan hasil final.

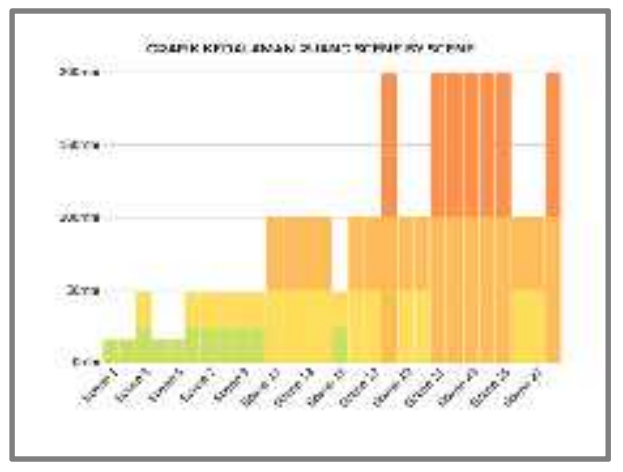

Gambar 16. Gambaran grafik meingkatnya kedalaman ruang dalam scene by scene
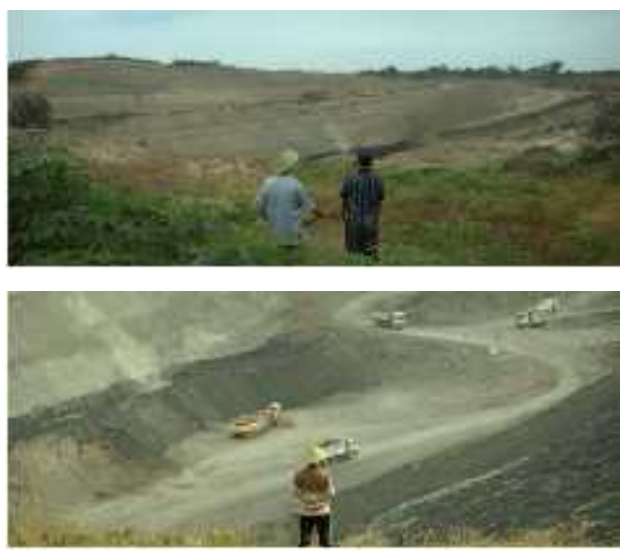

Gambar 17. Perbandingan meningkatnya kedalaman ruang pada scene 2 dan scene 28

Perubahan kedalaman ruang dengan signifikan juga dapat dilihat dari beberapa shot dimana scene 2 dan scene 28 memiliki kedalaman ruang yang sangat berbeda, perubahan tersebut terjadi akibat dari perubahan konflik internal yang sebelumnya masih dalam tahap awal atau sedikit menuju konflik yang semakin ke tahap akhir atau semakin banyak, emosi kebimbangan dalam diri Pak Yusni semakin bertambah dimana harus menyesali apa yang dia perbuat.

Gambar diatas memperlihatkan bagaimana perubahan kedalaman ruang yang signifikan antara scene 2 (gambar kiri) dan scene 28 (gambar kanan), dimana perubahan kedalaman ruang tersebut timbul karena pengaruh dari perubahan focal length $18 \mathrm{~mm}$ pada scene 2 dan focal length 200mm pada scene 28. Meningkatnya kedalaman ruang yang signifikan, pembuatan shot dengan sengaja menempatkan komposisi shot, shot size, blocking tokoh yang sama agar penonton dapat melihat kedalaman ruang yang terus naik pada film fiksi "Huma Amas". Penempatan blocking tokoh dibuat 
sama ingin menujukan repetisi yang memudahkan penonton mengingat shot yang sama pada scene 2 .

Penggambaran pada visual scene 17 diatas memanfaatkan efek kedalaman ruang yang semakin dalam dan semakin dekat antara foreground dan background dikarenakan focal length yang digunakan yaitu focal length 50-100mm, efek kedalaman tersebut juga ikut meningkat mengikuti permasalahan yang konflik yang semakin meningkat pula pada plot naratif film fiksi ini. Efek kedalaman ruang yang diolah menjadi sebuah framing yang memiliki visual storytelling dan dapat menyampaikan makna Pak Yusni seperti dihadang musuh dengan menempatkan karakter Pak Hasan dan Pak Noor dibagian foreground (efek menjadi membesar) dan Pak Yusni dibagian midground/background dengan blocking ditempatkan pada posisi tengah.

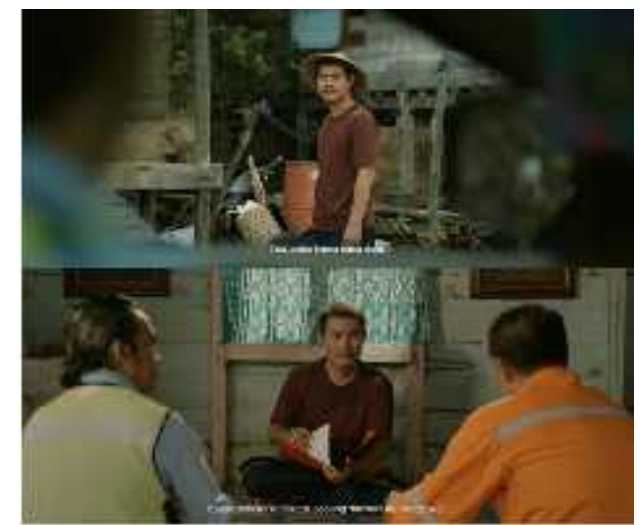

Gambar 18. Kedua shot diatas memiliki makna pada kedalaman ruang bagian foreground dan background

\section{KESIMPULAN}

Film fiksi "Huma Amas" ini dibuat dan dikerjakan dengan konsep membangun kedalaman ruang sebagai representasi konflik internal tokoh utama. Tujuan dari pembuatan film ini adalah memberikan sebuah kisah yang tidak banyak masyarakat ketahui bahwasannya para petani di Kalimantan Timur memiliki masalah sosial, ekonomi hingga politik yang mereka harus hadapi melawan perusahaan tambang batubara.

Konsep kedalaman (depth of field) ruang yang dibangun pada film fiksi "Huma Amas" bertujuan untuk merepresentasikan emosi dan konflik internal atau batin yang dirasakan tokoh utama. Membangun kedalaman ruang menjadi salah satu gaya penyutradaraan pada film "Huma Amas" bagaimana sutradara mengeksplorasi dan bereksperimen dengan kedalaman ruang yang menggunakan focal length lensa, dengan konsep ini sutradara secara objektif memberikan pemaknaan dari dalam gambar atau frame untuk mewakilkan konflik internal atau konflik batin. Kedalaman ruang yang dibangun mengikuti alur tangga dramatik yang selalu meningkat hingga selesai, dari eksposisi, hingga klimaks dan penyelesaian.

Meningkatnya masalah setiap naiknya babak pada tangga dramatik di ikuti kedalaman ruang (depth of field) dan focal length pada lensa juga ikut meningkat dari 
focal length $16 \mathrm{~mm}$ hingga $200 \mathrm{~mm}$. Meningkatnya focal length lensa juga memberikan efek ilusi depth yang diciptakan dari lensa, sisi focus dan out focus, foreground, midground dan background. Perubahan efek tersebutlah yang menjadi pemaknaan konflik batin yang dirasakan tokoh utama, penonton tidak hanya harus mengikuti dan memaknai ceritanya saja tetapi penonton dapat mengambil pemaknaan dari gambar yang disajikan pula.

\section{DAFTAR PUSTAKA}

Boggs, Joseph M. terjemahan Asrul Sani. 1992. Cara Menilai Sebuah Film (The Art of Watching Film). Jakarta: Yayasan Citra.

Bordwell, David. Thompson, Kristin. 2008. Film Art: An Introduction. New York: McGraw-Hill.

Brown, Blain. 2012. Cinematography: theory and practive image making for cinematographers and directors. Oxford: Focal Press.

Harymawan, RMA. 1986. Dramaturgi. Bandung: Remaja Rosdakarya Offset.

Lewin, K. 1948. The special case of Germany. In Lewin, G. W. (Ed.), Resolving Social Conflict. London: Harper \& Row.

Livingstone, Don. 1968. Film and Director. Newyork : Capricorn Book.

Marseli, Sumarno. 1996. Dasar-Dasar Apresiasi Film. Jakarta: Grasindo.
Mascelli, Joseph V. 2010. Lima Jurus Sinematografi. Jakarta: Fakultas Film dan Televisi IKJ.

Mercado, Gustavo. 2011. The Filmmaker's Eye. Oxford: Focal Press.

Naratama. 2004. Menjadi Sutradara Televisi: Dengan Single dan Multi Camera. Jakarta: Grasindo.

Pratista, Himawan. 2008. Memahami Film. Yogyakarta: Homerian Pustaka. , 2017. Memahami Film Edisi 2. Yogyakarta: Montase Press.

Ramadhan, Rakhmad Maulana. "Dinamisasi Shot Pada Sinematografi Film Sedeng Sang" Skripsi Karya Seni S1, Institut Seni Indonesia Yogyakarta, 2016.

Seger, Linda. 1987. Making a good script great. New York: Samuel French Trade.

Sobur, Alex. 2003. Psikologi Umum. Bandung: Pustaka Setia.

Sumarthana. 1983. Anekdot-anekdot Dalam Kehidupan Sehari-hari, Jakarta: Sinar Buana Pers.

Suwarsono, A.A. Pengantar Film. Yogyakarta: Badan Penerbit ISI Yogyakarta, 2010.

Ward, Peter. 2003. Picture Composition for Film and Television Second Edition. Oxford: Focal Press.

Zoebazary, Ilham. 2010. Kamus Istilah Televisi \& Film. Jakarta: PT. Gramedia Pustaka Tama 